\title{
THE CASE FOR CREDENTIALS, CAPABILITY BUILDING AND FUTURE PROOFING AT OTAGO POLYTECHNIC
}

\author{
Oonagh McGirr
}

\section{INTRODUCTION}

At the time of writing, the New Zealand vocational education sector is entering a new era. Significant changes to the structure and remit of constituent institutions are proposed by the Minister for Education. While Otago Polytechnic is recognised as a leader in the tertiary sector, specifically in the field of vocational education and training (VET), any shift in shape or structure requires us to demonstrate agility and a willingness to embrace the future. As we position ourselves to respond to the unfolding changes ahead, during what will undoubtedly be a period of flux and uncertainty, there is merit in considering how, as a community of learning and teaching, we may also serve the demands of the tertiary sector employment landscape. If we are to deliver an exemplary experience to our learners, we need to be the best version of our professional selves, modelling the same values which underpin our mission to build capability and realise potential', whilst demonstrating the skills, knowledge and attributes of highly capable, future-focused tertiary education practitioners.

\section{BACKGROUND}

\section{Reform of Vocational Education}

On February 13, 2018, the Prime Minister of Aotearoa-New Zealand, the Rt Hon Jacinda Ardern, foregrounded the imminent announcement from the Ministry of Education by providing a taste of what was to come for the vocational education sector (VET). This small island(s) nation in the southern corner of the so-called developed world needed to reduce its reliance on 'importing skills' and had to focus on responding to the requirements and expectations of a full-employment economy by creating more flexible learning opportunities and providing accessibility for the workplace and work-based learner (Ardern, 2019). One day later, on February 14, 2019, the Minister of Education, the Hon Chris Hipkins, unveiled his vision for a more unified sector predicated on the intention to tackle the seemingly broken sector of institutes of technology and polytechnics (ITP).

In summary, the 16 individual entities across the country would merge into one mega-ITP (to be known as the New Zealand Institutes of Skills and Technology [NZIST]) in order to provide better learning opportunities for the regions, and enable a collective and integrated approach to vocational education whilst addressing the so-called Auckland problem of too many polytechnic cooks spoiling an over-seasoned metropolitan broth. The contentious existence of out-of-region competition would end (and so presumably would the perceived failings of a sector in crisis - financial bailouts, chronic inability to innovate, and variable parity of learner experience between and across the islands' ITPs).

A period of national consultation followed, between February and April with a final announcement made on August I, 2019 (Ministry of Education, 2019), a month later than original time frame of 'mid-year' communicated by the government at the time of the initial announcement. 
As an institution, Otago Polytechnic developed a collectivised institutional reply to the Minister's original Reform of Vocational Education (RoVE) proposal (Executive Leadership Team, 2019). The detailed submission, intended to articulate a refinement to the proposed reform addressed the several key areas, and provided a visual model for the new national entity (see Figure I.). Otago Polytechnic worked as a collective and in continuous consultation, to prepare a robust (re)proposal, drawing on the considerable expertise of its staff and stakeholders. Otago Polytechnic leadership invited feedback and suggestions from all parts of the community during the consultation period. A process of drafting and re-drafting allowed for new and emerging ideas to be incorporated and tweaks to be made with a clear intention of providing an informed framework for implementation and practice, based on the considerable experience of the Otago Polytechnic collective and its documented and sustained success.

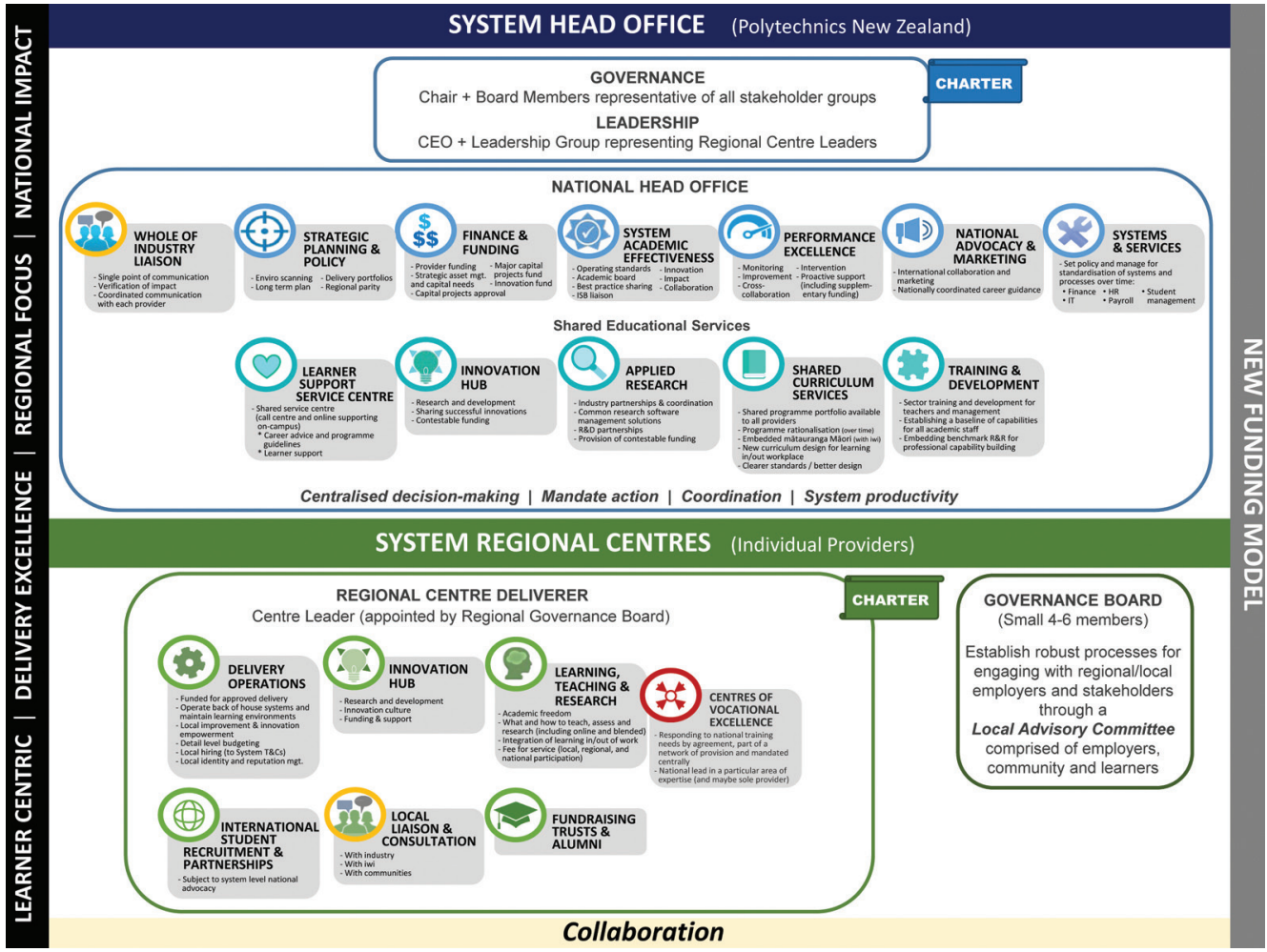

Figure I. Otago Polytechnic Submission on the Reform of Vocational Education - proposed model for NZIST.

In summary, the response to the RoVE proposal comprehensively outlined the structure of the Vocational Education system, with specific focus on:

1. the future role of Industry Skills Bodies (ISB)

2. concerns and solutions regarding a number of learning and teaching issues (shared curriculum services, academic freedom, online learning definition of vocational education, teaching of degrees and post-graduate programmes)

3. the purpose and function of the proposed Centres of Vocational Excellence (COVEs)

4. the nature and value of applied research

5. the need for investment in system-wide capability

6. sector funding

7. issues arising for consideration during the imminent transition period

8. a range of issues for NZIST yet to be considered. 
Post-consultation, on August 1, 2019, the Minister confirmed in a series of broadcast meetings that the RoVE was to move to implementation stage (following necessary legislative changes), albeit with some changes in nomenclature. The full documentation revealed a move away from a centre and branch model to a head office and subsidiary conceptualisation contained, curiously, in the Otago Polytechnic response to the Minister's original proposal. We infer from this outcome a small degree of success in influencing the final operational model for the ITP sector.

Additional detail regarding the establishment process of NZIST was made available with specific information about the partner bodies to be created, whose purpose is to work alongside ITPs to prepare the vocational workforce of the future. A key change to be effected is the creation of Workforce Development Councils (WDCs) in 2020 and the disestablishment of ISBs. This could imply that the academic freedom of individual ITPs and their staff may be compromised, curtailed or, in the worst case, simply dispensed with, despite the enshrinement of this key principle in law.

\section{Baseline to benchmark}

At Otago Polytechnic, we acknowledge the need to set high expectations in pursuit of building capability and realising the potential of our learning and teaching community of stakeholders - our students, staff, industry and community partners (McGirr, 20 I8). In the most recent discussions of our Executive Leadership Team, we have conceptualised the progress we wish to achieve; moving from a place of strength and acknowledged high performance, and reinforcing commitment to continuous improvement in pursuit of holistic performance excellence. Not content with achieving NZQA Category I provider status (twice) and the prestigious Baldrige-affiliated Performance Excellence Study Award (PESA) for organisational excellence in 2018, we remain focused on further uplift in terms of organisational performance. We describe this as moving from baseline to benchmark. In practical terms, our aim is to move from a good level of basic performance to a position of sustained high performance in all areas of institutional practice.

As our response to the initial proposal outlined, we sought to challenge constructively the blunt articulation of fixing a supposedly broken sector, which in itself seemed an erroneously simplistic solution. Equally, we noted that there are aspects of the sector which would benefit from a more holistic approach to resourcing and delivery. In our reply, we voiced our support for the consolidation of work-place training and apprenticeships in an appropriately resourced, fit-for-purpose, future-focused national network of VET provision. We posited that if we are to engender the required uplift in sector capability for performance improvement and extension of reach, we certainly need a more collegial sector-wide approach to enabling success for our learners nationwide - collaboration is key!

\section{DIRECTION AND PROGRESS}

Otago Polytechnic has made much progress in delivering on the strategic imperatives articulated in its Strategic Directions document (Otago Polytechnic Executive, 2017). By stating explicitly the goals and objectives for our polytechnic, we have been able to support growth and achievement by living the values of accountability, caring, courage and empowerment. In working to a clear and simple brief, Otago Polytechnic has responded to the challenges already identified by its Council and Executive Leadership team (ELT), and subsequently articulated by the Minister in his proposal for reform, thereby ensuring the success of stakeholders through innovation and agility.

Within our one-page Strategic Directions document, we unequivocally acknowledge the need for innovation and the commitment to achieving improvement in performance and capability. Since 2017, Otago Polytechnic has effected several significant changes to support this intended improvement, creating specific teams and units to help us achieve this. These teams have, in turn, developed and implemented several key initiatives which speak to the needs of today and expectations of the future (Ministry of Education, 20I9, p. I), and demonstrate readiness to meet the articulated workplace and work-based imperative. 


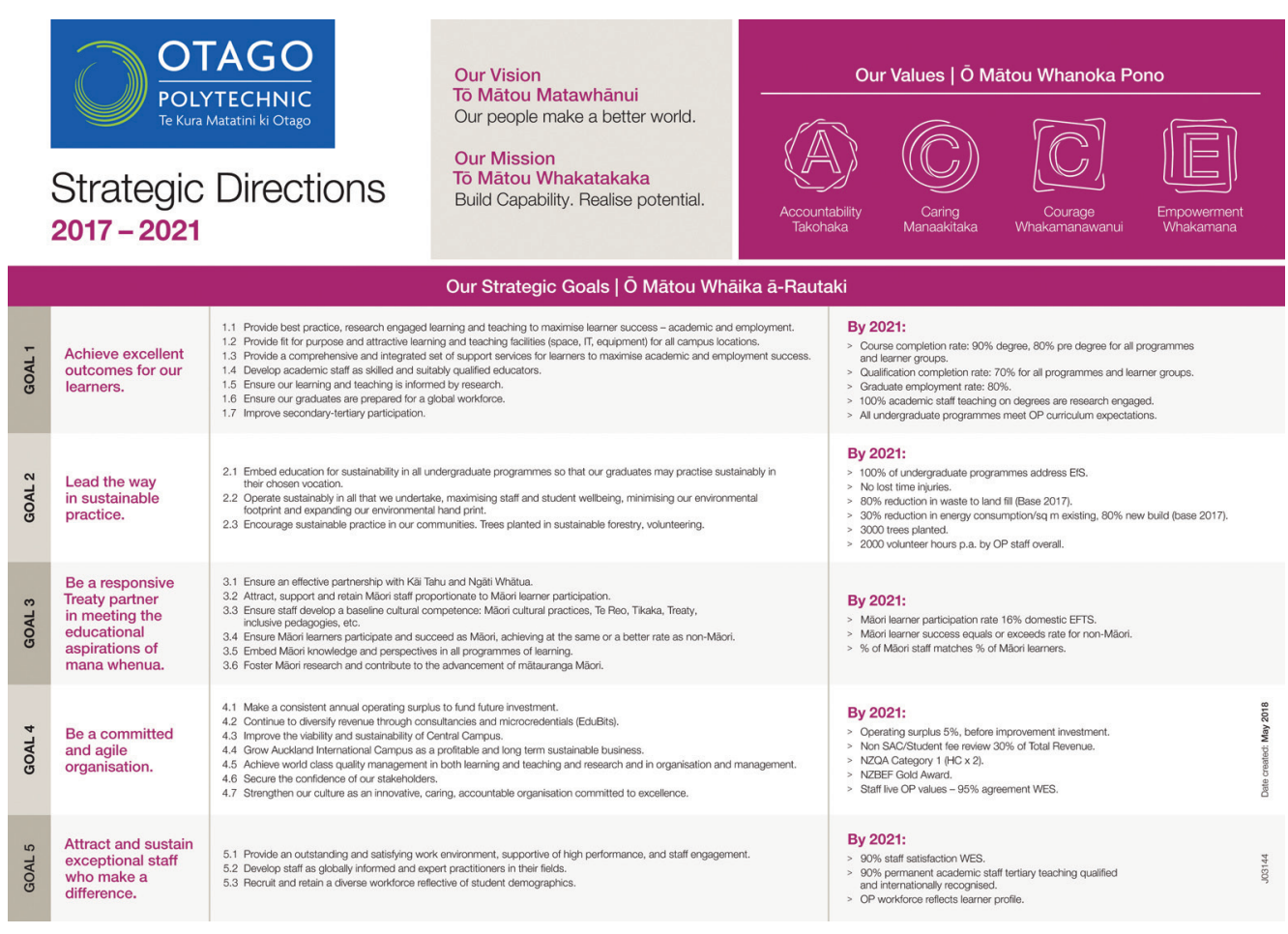

Figure 2. Otago Polytechnic, Strategic Directions 2017-2021.

\begin{tabular}{|l|l|}
\hline Goal 1 & Achieve excellent outcomes for our learners \\
\hline Goal 2 & Lead the way in sustainable practice \\
\hline Goal 3 & Be a responsive Treaty partner in meeting the educational aspirations of mana whenua \\
\hline Goal 4 & Be a committed and agile organisation \\
\hline Goal 5 & Attract and sustain exceptional staff who make a difference. \\
\hline
\end{tabular}

Figure 3. Detail of Otago Polytechnic, Strategic Goals in Otago Polytechnic Strategic Directions 20I7-202I.

\section{BUILDING CAPABILITY}

The specific initiatives led by Otago Polytechnic in its drive to prepare our people for the future encompass flexible teacher training, micro-credentials and an employability self-assessment system.

In 2016, Otago Polytechnic established an articulated portfolio of Learning and Teaching Services (LTS) designed to support our teachers to respond to, and embody, the profile of the future-focused teacher (McGirr, 20 I8). With the formation of the LTS, we signalled our institutional emphasis on preparing our teachers, equipping them with the skills, knowledge and attributes to engage fully with learners who will face an ever-changing employment landscape (Deloitte, 20 I8). Implicit in creating this single academic services portfolio was the notion of an integrated approach to quality development and design, which draws on a collaborative model of engagement with staff across the organisation. 


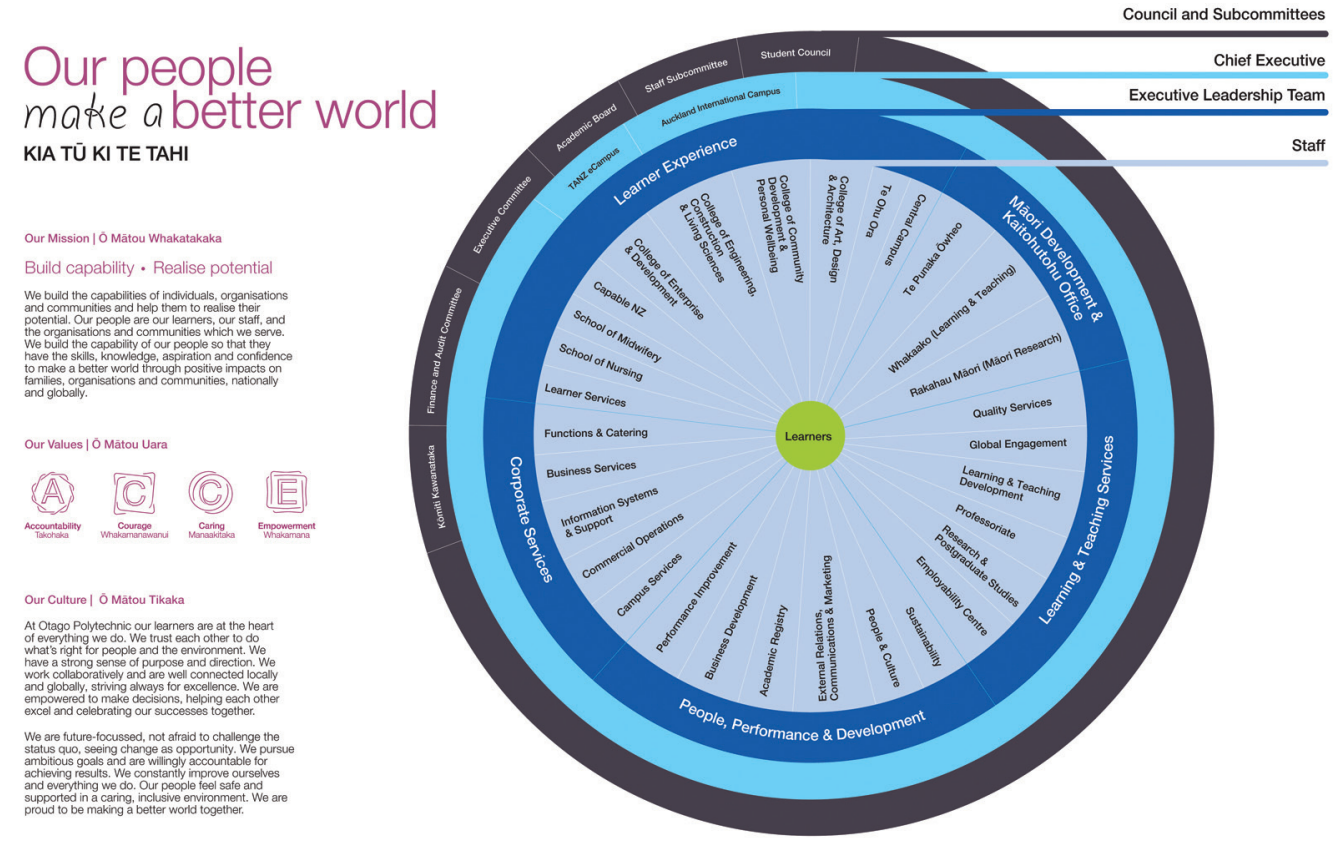

OTAGO POLYTECHNIC ORGANISATION STRUCTURE

Figure 4. Otago Polytechnic Organisation Structure

\section{Teacher training - the Graduate Diploma in Tertiary Education}

We acknowledge the need for our education practitioners to be 'adaptable, flexible and knowledgeable about the twenty-first century learning and teaching environments' (Deloitte, 20I8). With this imperative in mind, we have worked to re-design our core teaching qualification, the Graduate Diploma in Tertiary Education (GDTE), as an entirely work-based qualification, informed by our strategic Māori and sustainability frameworks (Otago Polytechnic, 2017). It is now a mandatory training requirement with full and flexible access for academic staff to support professional growth and achievement. The qualification is premised on the core concepts of dual professionalism competence in pedagogic practice, and discipline-led knowledge and skills rooted in co-constructed experiential learning. In this way, we seek to model our values in practice and provide flexible, blended learning opportunities for all. We require all our teaching staff to complete this inductive and incremental work-based training, and true to our philosophy, we offer four different pathways for incoming participants, from a fully taught experience to a scaffolded facilitated pathway, all predicated on a learner-centred, work-based approach.

\section{Learner Capability Framework - i am capable}

We believe that to be employable requires learners to have not only technical/specialist skills and knowledge, but also well-developed transferable skills, sometimes called soft skills, employability, or twenty-first century skills (Yorke, 2006), which we call 'Learner Capabilities'. The emergence of the soft skills agenda, coupled with the parallel shift to the applied experiential learning paradigm, informed the development, creation and implementation of the Otago Polytechnic self-assessment employability digital artefact and platform, 'i am capable'. 


\section{Why are transferable skills important?}

There are several reasons why we need to highlight transferable skills acquisition and recognition as inherent to our programmes of study:

- The nature of work is constantly changing.

- Employers are giving preference to those with well-developed transferable skills.

- They better equip graduates for new jobs yet to be created.

- The international mobility of graduates is enhanced.

'i am capable' empowers learners to develop work-ready capabilities, and connects the right learners to the right employers. Working with the digitally hosted portfolio, learners build an employability profile online, educators support learners as they develop their capabilities, and employers find the right graduates for their organisations. A key outcome for the learner is a comprehensive portable portfolio of validated evidence of their transferable skills for employability (Law, personal communication, August 27, 2019).

\section{Micro-credentials - EduBits}

Informed by many conversations and observations with our sector colleagues worldwide, Otago Polytechnic embarked upon an ambitious undertaking in 2016 to create a flexible assessment vehicle which enables the acknowledgement of skills, attributes and competencies for the workplace. Intended to fill a gap in the tertiary education market, Otago Polytechnic's micro-credentials help learners to formally recognise skillsets and validate specific career-expertise. EduBits (also known as digital micro-credentials) are nano-qualifications which are 'small enough to be manageable for busy people, but big enough to be meaningful to employer' (Otago Polytechnic, n.d.). Otago Polytechnic led the pilot for New Zealand Qualifications Authority in 20 17, resulting in the acknowledgement of micro-credentials on the New Zealand Qualifications Framework in July 2018.

\section{Workplace and work-based-Capable NZ}

Capable NZ is Otago Polytechnic's dedicated work-based learning unit, specialising in flipped curriculum and facilitated learning pathways. Capable NZ students undertake programmes of study which focus on work-based learning and workplace practice. In essence, learning opportunities are rooted in authentic work experience and reflections on, and in, practice. The Capable NZ model is predicated on learning in partnership, and draws on facilitative pedagogy to support learners achieve their qualifications.

The Capable NZ independent learner pathway (ILP) is characterised by four key stages: (i) self-assessment, (ii) identifying knowledge, (iii) facilitation, and (iv) assessment.

\section{FUTURE CAPABILITY}

Otago Polytechnic has been cognisant of the need to innovate continuously in pedagogy, product and process, and to do this we have set ourselves the task of taking the college to the workplace (Humber College, 20 I9). In the new era of global work and learning (Gallagher \& Maxwell, 2019), there is a need to acknowledge tacitly the soft skills revolution (Kamin, 2013) which informs institutional strategy and pedagogic practice. In the new national context of re-earning the institutional autonomy and associated quality assured brand of Otago Polytechnic ${ }^{2}$, government imperatives behove us to consider how we best achieve our mission whilst responding to the internal and external drivers, stakeholder needs, and industry demands across the employment landscape. 
The initiatives outlined provide, in great part, precisely what the Minister seeks in the quest for flexibility; workbased learning opportunities for all, and smaller, industry-endorsed, work-aligned credentials focused on job market capabilities and competencies. Similarly, our range of flipped-curriculum programmes achieved through a facilitated learning and teaching approach presents work-integrated learning as the norm, rather than an exception. By unbundling learning in this way, the emphasis is on acknowledging and developing the employability of the learner. We seek to provide the much-cited 'dual education' qualifications (Gallagher \& Maxwell, 20I9, p. 6) and workforce education as an integrated learner experience; in simple terms, we provide both academic knowledge and workplace skills rather than the former or the latter. Moreover, we do so in a way which maximises the work capital of each individual learner.

\section{CONCLUSION}

In consolidating our future focus at Otago Polytechnic, we seek to recognise and value what we do, and acknowledge and champion lifelong learning as the leading tenet of our mission and practice. Now, more than ever, is the time for us to capitalise on our values-driven innovation and sector leadership by continuing to demonstrate agility and resilience in the face of what me might call a certain uncertainty. ${ }^{3}$ Change is afoot, and while we have some detail in terms of the initial steps, there is much which is yet to be determined. This means, in real terms, there is an opportunity to lead and influence the state and status of the reformed version of our sector. Flexible teacher training, EduBits, 'i am capable' and Capable NZ offer some of those sought-after solutions which New Zealand requires if it is to enter the future with a well-equipped, current and capable workforce.

Oonagh McGirr, Deputy Chief Executive of Otago Polytechnic, is the strategic lead for academic development. She leads a diverse portfolio of directorates: Learning and Teaching Development; Research and Postgraduate; Global Engagement; Employability, the Otago Polytechnic Professoriate and the UNESCO endorsed Open Education Resource Universitas. Oonagh has worked in international higher education for over two decades in both the public and private sectors. She has established and led academic services units; developed education strategy for regional and national government bodies; devised and delivered staff development and upskilling programmes for higher education practice; and led institutional learning and teaching accreditation and recognition. She has taught on foundation, undergraduate and postgraduate programmes in modern foreign languages, cultural studies, linguistics, teacher education and research in multidisciplinary settings at new and legacy higher education institutes in Europe and the Middle East. Her research interests are teacher identity in practice in higher education, higher education leadership practice and the development of sustainable continuing professional development frameworks for higher education practitioners. Oonagh is a Fellow of the Royal Society of the Arts.

I Otago Polytechnic Vision, Mission and Values. Dunedin, 2017.

2 Otago Polytechnic Vision, Mission and Values. Dunedin, 2017.

3 After Maturana and Varela in Autopoiesis and Cognition:The Realization of the Living. 1980. 


\section{REFERENCES}

Ardern, H. J. (2019, February 13th). Annoucnment regarding the Future of the ITP sector and Vocational Education in Aotearoa New Zealand. Wellington, Aotoearoa-New Zealand: Ministry of Education.

Deloitte. (2018, September). Higher Education for A Changing World: ensuring the 100 year life is a better life. Sydney: Deloitte Touche Tohmatsu.

Executive Leadership Team . (2019, April 26). Otago Polytechnic Submission on the Reform of Vocational Education. Dunedin, Otago, New Zealand.

Fanghanel, J. (201 I). Being and Academic. Abingdon, Oxen: Routledge.

Gallagher, S., \& Maxwell, N. L. (2019, January). Community Colleges and the New Era of Work and Learning. Working Paper 66. Princeton, New Jersey, USA.: Mathematical Policy Research.

Humber College, C. (2019, May ). Global Polytechnic Partner Alliance Planning Meeting . EduBits et al . Humber, Ontario, Canada.

Jones-Schenk, J. (20 I 8). Alternative Credentials for Workforce Development. The Journal of Continuing Education in Nursing, 49(I0), 449-450.

Kamin, M. (2013). Soft Skills Revolution. San Francisco:Wiley.

Law, B. (2019, August 27). Re: i am capable - email correspondence . Dunedin, Otago, New Zeland .

Matthews, K., Garratt, C., \& Macdonald, D. (20 I 8). The Hlgher Education Landscape:Trends and Implications. Discussion Paper. Univeristy of Queensland, Insittute for Learnign and Teaching Innovation. Brisbane: Univeristy of Queensland.

Maturana, H., \& Varela, F. (1980). Autopoiesis and Cognition: The Realization of the Living. Dordrecht, Holland: D. Reidel Publishing Company.

McGirr, O. (2018, December ). On Capability-building for Continuous Improvment: Positioning Learning and Teaching Professional Development at Otago Polytechnic. (O. McGirr, D. McMaster, \& S. Bolland, Eds.) Scope Contemporary Research Topics, learning \& teaching (5), 19-25.

Ministry of Education. (2019). Reform of Vocational Education: Information for staff of institutes of technology and polytechnics (ITPs). Wellington, New Zealand Aotearoa: Government of New Zealand.

Otago Polytechnic . (2017). Sutainability Framework . Dunedin : Otago Polytechnic Executive Leadership .

Otago Polytechnic. (2018, August 16). Leading News. Retrieved from Otago Polytehcnic: https://otagopolytechnic.createsend.com/ campaigns/reports/viewCampaign.aspx?d=r\&c=C979058524BB496D\&ID=993023C0568367382540EF23F30FEDED\&tem $\mathrm{p}=$ False $\& \mathrm{t} x=0$

Otago Polytechnic. (2019, August 2). EduBits. Retrieved from EduBits NZ: www.edubits.nz

Otago Polytechnic Executive. (2017). Strategic Directions. Dunedin: Otago Polytechnic.

Otago Polytechnic Kaitahoutahou Office . (2017). Maori Strategic Framework . Dunedin : Otago Polytechnic .

Rimland, E., \& Raish, V. (2019). Microcredentials and Digital Badges: Overview, Definition and Benefits. Library Technology Reports Altech Source.

Treadwell, M. (2019, January 17). The Future of Learning. Retrieved from Education Central.: https://educationcentral.co.nz/the-futureof-learning/

Yorke, M. (2006). Employability in Higher Education: what is is and what is is not. York, England: Higher Education Academy . 